\title{
Chapter 11 \\ Census Coverage of the Native Hawaiian or Pacific Islander Population
}

\begin{abstract}
In general, the count of Native Hawaiian or Pacific Islanders Alone or in Combination in the U.S. Census is relatively accurate. The net undercount rate for Native Hawaiian or Pacific Islanders Alone or in Combination in 2010 was $1.0 \%$ compared to a net overcount of $0.8 \%$ for the Non-Hispanic White Alone population. The omissions rate for Native Hawaiian or Pacific Islanders Alone or in Combination (7.9\%) is about double the rate for Non-Hispanic White Alone $(3.8 \%)$. The Native Hawaiian or Pacific Islanders Alone or in Combination demographic group with the highest net undercount rate was males age 18-29 who had a net undercount rate of $8.0 \%$ in 2010 . This is the only net undercount rate among Native Hawaiian or Pacific Islanders that was statistically significantly different than zero.
\end{abstract}

\subsection{Introduction}

In reporting Census data on the Native Hawaiian or Pacific Island population it is very important to be clear about how the group is defined. Starting in the 2000 Census, people were allowed to select more than one race in the Census questionnaire (U.S. Office of Management and Budget 1997) and race is often reported two different ways in Census Bureau reports. One category is the number of people who only select Native Hawaiian or Pacific Islander (referred to as Native Hawaiian or Pacific Islander Alone) and the second category is those in the first group plus those who select Native Hawaiian or Pacific Islander along with at least one other race (referred to as Native Hawaiian or Pacific Islander Alone or in Combination).

There is a substantial difference between the number of people who are in the Native Hawaiian or Pacific Islander Alone category and those in the Native Hawaiian or Pacific Islander Alone or in Combination category. In the 2016 American Community Survey conducted by the Census Bureau there were about 600,000 people who marked Native Hawaiian or Pacific Islander Alone and 1.4 million who marked Native Hawaiian or Pacific Islander and some additional race. Except for data on trends over time, Native Hawaiians or Pacific Islanders Alone or in Combination is the population examined in this Chapter. This is the most inclusive definition and consistent with advice of the U.S. Office of Management and Budget (2001). 
It is also noteworthy that the number of Native Hawaiians or Pacific Islanders Alone or in Combination increased by $40 \%$ between 2000 and 2010 (U.S. Census Bureau 2012). About half of the Native Hawaiian or Pacific Islander Alone or in Combination population resides in Hawaii or California.

This population is not only increasing rapidly but given the unique history and evolution of Native Hawaiians or Pacific Islanders in the U.S. population, they fall into the category of cultural and linguistic minorities discussed by Harkness et al. (2014). Cultural and linguistic minority are often considered a hard-to-count population which means they are more difficult to enumerate accurately in the census.

The Demographic Analysis method does not produce data on Census coverage for Native Hawaiian or Pacific Islanders, so all the data in this section comes from the Census Bureau's Dual-Systems Estimates (DSE) method. Keep in mind the sample size of Native Hawaiians and Alaskan Natives in the Post-Enumeration Survey used in the DSE method is smaller than most other groups so small differences between rates may not be significant.

\subsection{Census Coverage of Native Hawaiian or Pacific Islanders Alone or in Combination}

Table 11.1 shows net undercount rates from DSE for Native Hawaiian or Pacific Islanders Alone or in Combination broken down by age and sex. Data for the youngest age groups (0-9) are not presented in Table 11.1 because there is strong evidence that the coverage estimates of young children in the DSE in 2010 are problematic (O'Hare et al. 2016).

In the 2010 Census, the net undercount rate for all Native Hawaiian or Pacific Islanders Alone or in Combination was $1.0 \%$ (Table 11.1) and the rate is not statistically significant different from zero. By comparison, there was a statistically significant net overcount of Non-Hispanic White Alone population of $0.8 \%$.

As with the other racial and Hispanic Origin groups examined in this book, the net undercount rate for the total Native Hawaiian or Pacific Islander Alone or in Combination population masks some important differences by age and sex. However, within the Native Hawaiian or Pacific Islander Alone or in Combination population the differences by age and sex are not as pronounced as they are in Black or Hispanic populations.

The highest net undercount in Table 11.1 is for males age 18-29. The net undercount rate for Native Hawaiian or Pacific Islander males in this age range is $8.0 \%$ and this is the only net undercount estimate for Native Hawaiians or Pacific Islanders Alone or in Combination that is statistically significantly different than zero. The relatively high net undercount of males age 18-29 is consistent with high net undercounts for this age/sex group in most other race and Hispanic groups. Young adult males are a demographic group that has been identified as difficult to enumerate regardless of race or ethnicity in many countries (Simpson and Middleton 1997). 
Table 11.1 Net undercount rates for Native Hawaiians or Pacific Islanders Alone or in Combination and Non-Hispanic White Alone populations in the 2010 census by age and sex

\begin{tabular}{l|l|l}
\hline & $\begin{array}{l}\text { Native Hawaiian or Pacific Islanders } \\
\text { Alone or in Combination }\end{array}$ & $\begin{array}{l}\text { Non-Hispanic White } \\
\text { Alone }\end{array}$ \\
\hline Total & -1.0 & $\mathbf{0 . 8}$ \\
\hline Age $10-17$ & 1.1 & $\mathbf{1 . 8}$ \\
\hline Age $18-29$ males & $\mathbf{- 8 . 0}$ & $\mathbf{1 . 5}$ \\
\hline Age $18-29$ females & 1.9 & $\mathbf{1 . 1}$ \\
\hline Age 30-49 males & 2.0 & $\mathbf{- 2 . 1}$ \\
\hline Age 30-49 females & -1.2 & $\mathbf{0 . 7}$ \\
\hline Age 50+ males & -0.4 & $\mathbf{0 . 6}$ \\
\hline Age 50+ females & -1.4 & $\mathbf{2 . 2}$ \\
\hline
\end{tabular}

Source U.S. Census Bureau (2012). "2010 Components of Census Coverage for Race Groups and Hispanic Origin by Age, Sex, and Tenure in the United States". DSSD 2010 CENSUS COVERAGE MEASUREMENT MEMORANDUM SERIES\#2010-E-51, U.S. Census Bureau, Washington, DC. Table C

A negative sign reflects a net undercount. The signs here are reversed from the source report in order to keep directionality consistent within this publication

Figures in BOLD are statistically significantly different from zero

\subsection{Census 2010 Omissions Rates for Native Hawaiian or Pacific Islanders Alone or in Combination and Non-Hispanic Whites Alone}

Recall that the net census undercount rate is a balance between people omitted and those included erroneously (mostly double counted). The omissions rate captures the share of a group missed in the Census. DSE is the only method that shows omissions rates.

In many ways the omissions rate is a more meaningful statistic because in the net undercount calculation, omissions can be cancelled out by erroneous inclusions or double counting. A net undercount of zero could be the result of no one missed and not one double counted, or for example, $10 \%$ missed, and $10 \%$ double counted.

The omissions rate for Native Hawaiian or Pacific Islanders Alone or in Combination $(7.9 \%)$ is slightly more than double that of the Non-Hispanic White Alone population $(3.8 \%)$ but omissions rates vary by age and sex. To a large extent the omissions rates among Native Hawaiian or Pacific Islanders Alone or in Combination reflect the same age/sex demographic pattern as the net undercount rates (Table 11.2).

Like the results for net undercount rates, Native Hawaiian or Pacific Islander Alone or in Combination males age 18-29 had a very high omissions rate. The omissions rate for Native Hawaiian or Pacific Islander Alone or in Combination males 18-29 was $15.7 \%$ which is almost twice as high as the overall omissions rate for the Native Hawaiian or Pacific Islanders Alone or in Combination population. The omissions 
Table 11.2 Omissions rates for Native Hawaiians and Pacific Islanders Alone or in Combination and Non-Hispanic White Alone populations in the 2010 census by age and sex

\begin{tabular}{l|l|l}
\hline & $\begin{array}{l}\text { Native Hawaiian or Pacific Islander Alone } \\
\text { or in Combination }\end{array}$ & $\begin{array}{l}\text { Non-Hispanic White } \\
\text { Alone }\end{array}$ \\
\hline Total & 7.9 & 3.8 \\
\hline Age $10-17$ & 5.0 & 3.1 \\
\hline Age $18-29$ male & 15.7 & 6.6 \\
\hline Age $18-29$ female & 7.7 & 6.2 \\
\hline Age 30-49 male & 6.4 & 6.2 \\
\hline Age 30-49 female & 7.2 & 3.0 \\
\hline Age 50+ male & 4.5 & 3.5 \\
\hline Age 50+ female & 7.6 & 1.7 \\
\hline
\end{tabular}

Source U.S. Census Bureau (2012). "2010 Components of Census Coverage for Race Groups and Hispanic Origin by Age, Sex, and Tenure in the United States". DSSD 2010 CENSUS COVERAGE MEASUREMENT MEMORANDUM SERIES\#2010-E-51, U.S. Census Bureau, Washington, DC. Table C

rate for Native Hawaiian or Pacific Islanders Alone or in Combination males age $30-49(6.4 \%)$ is relatively low compared to the overall omissions rate $(7.9 \%)$.

\subsection{Coverage of Native Hawaiian or Pacific Islanders Alone or in Combination by Tenure}

Table 11.3 shows net undercount rates and omissions rates from the 2010 Census DSE analysis for the population living in owner-occupied housing units and renteroccupied housing units among Native Hawaiian or Pacific Islanders Alone or in Combination and Non-Hispanic White Alone.

Like most other demographic groups examined in this book, there is a big difference in census coverage between the population living in owner-occupied housing units and those living in rental units. The net undercount rate for the population of Native Hawaiians or Pacific Islanders Alone or in Combination living in renteroccupied housing units is $3.7 \%$ (which is statistically significantly different than zero) compared to a net overcount of $1.8 \%$ for Native Hawaiians or Pacific Islanders Alone or in Combination living in owner-occupied housing units. The net coverage gap between Native Hawaiian and Pacific Islanders Alone or in Combination and Non-Hispanic Whites is more than 4 percentage points for renters compared to only 1 percentage point for owners.

Native Hawaiian or Pacific Islanders alone or in Combination have higher omissions rates than Non-Hispanic White Alone in both owner and rental situations. Among the population living in owner-occupied housing units, the omissions rate was $5.6 \%$ for Native Hawaiian or Pacific Islanders Alone or in Combination and 
Table 11.3 2010 census net undercount rates and omissions rates for Native Hawaiians and Pacific Islanders Alone or in Combination and Non-Hispanic White Alone by Tenure

\begin{tabular}{l|l|l|l}
\hline \multicolumn{2}{l|}{} & $\begin{array}{l}\text { Native Hawaiians and } \\
\text { Pacific Islanders Alone } \\
\text { or in Combination }\end{array}$ & $\begin{array}{l}\text { Non-Hispanic White } \\
\text { Alone }\end{array}$ \\
\hline \multirow{2}{*}{ Percent Undercount (\%) } & Owners & 1.8 & $\mathbf{0 . 8}$ \\
\cline { 2 - 4 } & Renters & $\mathbf{- 3 . 7}$ & 0.9 \\
\hline Percent Omissions (\%) & Owners & 5.6 & 3.0 \\
\cline { 2 - 4 } & Renters & 10.1 & 6.4 \\
\hline
\end{tabular}

Source U.S. Census Bureau (2012), DSSD 2010 CENSUS COVERAGE MEASUREMENT MEMORANDUM SERIES 2012, 2010-E-51, Table B

Note The directionality of undercounts and overcounts have been reversed from the original table in order to keep them consistent within this publication In order words, a negative sign implies an undercount

Figures in BOLD are statistically significantly different from zero

3.0\% for Non-Hispanic White Alone. Among renters the omissions rate for Native Hawaiian or Pacific Islanders Alone or in Combination Native Hawaiian or Pacific Islanders Alone was $10.1 \%$ compared to $6.4 \%$ for Non-Hispanic White Alone. The omissions rate for Native Hawaiians or Pacific Islanders Alone or in Combination for renter $(10.1 \%)$ is higher than that of owners $(5.6 \%)$ which again show the impact of home-ownership on Census accuracy.

\subsection{Trend Data from 1990 to 2010}

Table 11.4 shows net undercount rates for 1990, 2000, and 2010 Censuses for Native Hawaiian or Pacific Islanders Alone and Non-Hispanic Whites Alone based on the Census Bureau's DSE method. Note that the Native Hawaiian or Pacific Islander "Alone" race definition is used in this table to make categories consistent over time.

The net undercount rates for Native Hawaiians or Pacific Islander Alone have decreased steadily over time from $2.4 \%$ in 1990 , to $2.1 \%$ in 2000 , to $1.3 \%$ in 2010 . While the improvement since 1990 is positive it was very small, and it should be noted that Native Hawaiians and Pacific Islanders still have a net undercount while Non-Hispanic Whites have an overcount.

The difference between the census coverage rates of Native Hawaiian or Pacific Islanders has decreased slightly from 3.1 percentage points in 1990 to 2.1 percentage points in 2010. A small positive improvement. 
Table 11.4 Net undercount rates for Non-Hispanic Asian and Non-Hispanic White 1990, 2000, and 2010

\begin{tabular}{l|r|r|l}
\hline & 2010 & 2000 & 1990 \\
\hline Non-Hispanic White & $\mathbf{0 . 8}$ & $\mathbf{1 . 1}$ & $\mathbf{- 0 . 7}$ \\
\hline Native Hawaiian and Pacific Islanders & -1.3 & -2.1 & $\mathbf{- 2 . 4}$ \\
\hline
\end{tabular}

Source U.S. Census Bureau (2012). "2010 Census Coverage Measurement Estimation Report: Summary of Estimates of Coverage for Persons in the United States". DSSD 2010 CENSUS COVERAGE MEASUREMNET MEMORANDUM SERIES\#2010-G-01, U.S. Census Bureau, Washington, DC. Table 7

A negative sign reflects a net undercount. The signs here are reversed from the source report in order to keep directionality consistent within this publication

Note In this table the race categories are race alone, not race alone or in combination. The data are presented this way to make the 2010 categories consistent with the 1990 categories

Figures in BOLD are statistically significantly different than zero

\subsection{Summary}

Overall, the Native Hawaiian or Pacific Islander Alone or in Combination population had a small net undercount (1.0\%) compared to a small net overcount for the NonHispanic White Alone population. Native Hawaiian or Pacific Islander Alone or in Combination males age 18-29 had the highest net undercount rate of any age/sex group in this population and they had the highest omissions rate of any age/sex group. The net undercount rates for Native Hawaiian or Pacific Islanders have decreased from 1990 to 2010 but it should be noted that Native Hawaiians and Pacific Islanders still have a net undercount while Non-Hispanic Whites have an overcount.

\section{References}

Harkness, J., Stange, M., Cibelli, K. L., Mohler, P., \& Pennell, B. (2014). Surveying cultural and linguistic minorities. In R. Tourangeau, B. Edwards, T. P. Johnson, K. M. Wolter, \& N. Bates (Eds.), Hard-to-survey populations (pp. 245-269). Cambridge, England: Cambridge University Press.

O'Hare, W. P., Robinson, J. G., West, K., \& Mule, T. (2016). Comparing the U.S. decennial census coverage estimates for children from the demographic analysis and coverage measurement surveys. Population Research and Policy Review. https://doi.org/10.1007/s11113-016-9397-x.

Simpson, L. \& Middleton, E. (1997). Who is missed by a national census? A review of empirical results from Australia, Britain, Canada, and the USA, The Cathie Marsh Centre for Census and Survey Research. UK: University of Manchester.

U.S. Census Bureau. (2012). The native Hawaiian or Pacific Islanders population: 2010. In E. M. Hoeffel, S. Rostogi, \& H. Shahid (Eds.), 2010 census brief. Washington, DC: U.S. Census Bureau. 
U.S. Office of Management and Budget. (1997). Revisions to the standards for the classification of federal data on race and ethnicity. Statistical Policy Directive 15. Federal Register. Notice October 30, 1997. Available online at http://www.Whitehouse.gov/omb/fedreg_1997standards. U.S. Office of Management and Budget. (2001). Guidance on aggregation and allocation of data on race for use in civil rights monitoring and enforcement.

Open Access This chapter is licensed under the terms of the Creative Commons Attribution 4.0 International License (http://creativecommons.org/licenses/by/4.0/), which permits use, sharing, adaptation, distribution and reproduction in any medium or format, as long as you give appropriate credit to the original author(s) and the source, provide a link to the Creative Commons license and indicate if changes were made.

The images or other third party material in this chapter are included in the chapter's Creative Commons license, unless indicated otherwise in a credit line to the material. If material is not included in the chapter's Creative Commons license and your intended use is not permitted by statutory regulation or exceeds the permitted use, you will need to obtain permission directly from the copyright holder.

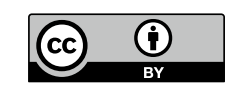

